\title{
Monodispersed ZnO Nanoparticles and Their Use in Heterojunction Solar Cell
}

\author{
Dinesh Patidar, Anusaiya Kaswan, N. S. Saxena, and Kananbala Sharma \\ Semi-Conductor and Polymer Science Laboratory, Department of Physics, University of Rajasthan, Jaipur 302004, India \\ Correspondence should be addressed to Dinesh Patidar; dinupatidar@gmail.com
}

Received 5 August 2013; Accepted 30 September 2013

Academic Editors: G.-R. Li, E. Poirier, and D. Zhang

Copyright ( 2013 Dinesh Patidar et al. This is an open access article distributed under the Creative Commons Attribution License, which permits unrestricted use, distribution, and reproduction in any medium, provided the original work is properly cited.

\begin{abstract}
Monodispersed $\mathrm{ZnO}$ nanoparticles have been synthesised in ethylene glycol medium using zinc acetate and sodium hydroxide at room temperature through ultrasonic treatment. The monodispersed ZnO nanoparticles were characterized by XRD, TEM, SEM, and optical spectroscopy. The results indicate that $\mathrm{ZnO}$ shows the hexagonal wurtzite structure having $8 \mathrm{~nm}$ average particle size with the band gap of $3.93 \mathrm{eV}$. ZnO nanoparticles blended with $\mathrm{P} 3 \mathrm{HT}$ show the improvement in the interchains and intrachains ordering as compared to pure P3HT. The power conversion efficiency of $\mathrm{P} 3 \mathrm{HT} / \mathrm{ZnO}$ solar cell is found to be $0.88 \%$, which is comparable with the result obtained by other researchers.
\end{abstract}

\section{Introduction}

Semiconducting nanocrystalline materials have been intensively investigated because of their fundamental scientific interest and many technological applications [1-3]. Among them, zinc oxide $(\mathrm{ZnO})$ is an important basic material from a versatile application point of view due to its large band gap $(3.37 \mathrm{eV})$, low cost, and luminescent properties [4]. It is widely used in many fields, such as UV lasers [5], catalyst [6], gas sensors [7, 8], transparent conductive oxide [9], varistors [10], and light emitting diodes $[11,12]$.

Besides these applications, $\mathrm{ZnO}$ is also a very attractive semiconductor for use in solar cells due to its abundance and low cost, nontoxicity, high electron mobility, low crystallization temperature, large exciton binding energy (60 meV), and easy synthesis. Recently, it is observed that $\mathrm{ZnO}$ can be used as electron acceptor to dissociate excitons produced in conjugated polymers. This combines the advantages of both organic semiconductors (flexibility, solutions processing) and inorganic semiconductors (stability, high mobility). This type of hybrid organic-inorganic solar cells can be fabricated by blending $\mathrm{ZnO}$ nanoparticles and conjugated polymer (bulk heterojunction: $\mathrm{BHJ}$ ) and also by impregnation of conjugated polymer on nanostructured $\mathrm{ZnO}$, which is coated on indium tin oxide (ITO). First successful attempt was made to fabricate $\mathrm{P} 3 \mathrm{HT} / \mathrm{ZnO}$ nanorods photovoltaic cell by replacing $\mathrm{TiO}_{2}$ [13]. In this case, a promising performance of the device based on $\mathrm{ZnO}$ nanorods was obtained, which is due to the ease of electron transport and collection. Ravirajan et al. [14] have reported the effect of nanoparticles morphology and interfacial modification on the performance of $\mathrm{P} 3 \mathrm{HT} / \mathrm{ZnO}$ photovoltaic device. They found that photovoltaic device based on nanorod structure treated with amphiphilic dye before deposition of P3HT polymer yields four times greater power conversion efficiency as compared to untreated device. The $1.6 \%$, and $0.9 \%$ power conversion efficiencies have been observed by blending $\mathrm{ZnO}$ nanoparticles with MEH-PPV [15] and P3HT, respectively. Olson et al. [16] have studied $\mathrm{ZnO}$ nanofiber electrodes impregnated with $\mathrm{P} 3 \mathrm{HT}$ and they obtained $0.53 \%$ efficiency in ITO/ZnO/P3HT/Ag devices. Peiró et al. [17] have observed $0.2 \%$ efficient ITO/ZnO/P3HT/Au devices after coating $\mathrm{ZnO}$ with a dye. Electrons are extracted from the $\mathrm{ZnO}$ conduction band $(4.35 \mathrm{eV})$ by ITO, while holes are extracted from the $5.2 \mathrm{eV}$ P3HT HOMO level by a high work function top contact such as $\mathrm{Au}$ or $\mathrm{Ag}$ in the $\mathrm{BHJ}$ configuration. It is noticed that the power conversion efficiency of the device based on $\mathrm{ZnO}$ nanorod arrays is even lower than that based on nanoparticles, which is partially due to the smaller interface area in the former devices. It is believed 
that the enhanced performance of device comes from the increased heterojunction area. The charge separation and transport in the device strongly depend on the morphology and orientation of the nanoparticles.

Therefore, the synthesis of monodispersed $\mathrm{ZnO}$ nanocrystals is a very important aspect from the point of view of its solar cell's applications because its properties depend strongly on their dimensions [18] and morphology. It has a strong tendency to agglomerate and at last become big conglomerations, which influence the efficiency of solar cells. Various methods have been developed for synthesizing low-dimensional $\mathrm{ZnO}$ nanostructures such as solvothermal method [19], hydrothermal method [20, 21], physical vapor deposition (PVD) [22], thermal decomposition [23], chemical vapor deposition (CVD) [24], metal-organic vapor-phase epitaxy [25], metal-organic CVD [26], templateassisted growth [27], sputtering [28], and various solution methods [29-33]. Recently, the synthesis of $\mathrm{ZnO}$ nanorods using an alcohol thermal process was reported [34]. In this work, we report a simple, inexpensive, and slightly modified alcohol thermal process for synthesis of monodispersed $\mathrm{ZnO}$ nanoparticles. In this process, monodispersed $\mathrm{ZnO}$ nanoparticles have been prepared at room temperature in place of low temperature condition using ultrasonic treatment and characterized through the X-ray diffraction (XRD), transmission electron microscope (TEM), scanning electron microscope (SEM), and optical spectroscopy. The prepared monodispersed $\mathrm{ZnO}$ nanoparticles have been used to fabricate $\mathrm{P} 3 \mathrm{HT} / \mathrm{ZnO}$ solar cell, which was characterized through the optical spectroscopy and electrical measurements.

\section{Experimental Details}

$\mathrm{Zn}(\mathrm{Ac})_{2} \cdot 2 \mathrm{H}_{2} \mathrm{O}, \mathrm{NaOH}$, ethylene glycol, and oleic acid have been purchased from Merk. ITO and P3HT have been procured from Sigma-Aldrich. All the reagents are of analytical grade and were used without further purification.

2.1. Synthesis of $\mathrm{ZnO}$ Nanoparticles. $\mathrm{ZnO}$ nanoparticles were prepared by an improved method derived from Spanhel and Anderson [35], Qian et al. [36], and Ge et al. [37]. A typical experiment to synthesize $8 \mathrm{~nm} \mathrm{ZnO}$ nanoparticles is as follows. $0.04 \mathrm{M}$ of $\mathrm{Zn}(\mathrm{Ac})_{2} \cdot 2 \mathrm{H}_{2} \mathrm{O}$ was dissolved in $100 \mathrm{~mL}$ of absolute ethylene glycol under magnetic stirring at $80^{\circ} \mathrm{C}$ and $0.04 \mathrm{M}$ of $\mathrm{NaOH}$ was also dissolved in $100 \mathrm{~mL}$ of absolute ethylene glycol using magnetic stirring for $20 \mathrm{~min}$. Then, ethylene glycol solution containing $\mathrm{NaOH}$ was dropped into ethylene glycol solution containing $\mathrm{Zn}(\mathrm{Ac})_{2} \cdot 2 \mathrm{H}_{2} \mathrm{O}$ at room temperature under strong magnetic stirring for 3 hrs. The mixture solution was treated ultrasonically for $30 \mathrm{mins}$. Then, $0.50 \mathrm{~mL}$ oleic acid as surfactant was added into the solution to avoid agglomeration of these nanoparticles. After this, monodispersed $\mathrm{ZnO}$ particles were obtained by centrifugation, throwing away the supernatant layer and the solid product was washed with ethanol, acetone, and deionized water sequentially. Then, monodispersed $\mathrm{ZnO}$ nanoparticles were dried in vacuum at room temperature.
2.2. Fabrication of Photovoltaic Devices. First of all, $10 \mathrm{mg} / \mathrm{mL}$ of $\mathrm{P} 3 \mathrm{HT}$ was dissolved in chloroform by magnetic stirrer. Ten $\mathrm{mg} / \mathrm{mL}$ of the above-obtained $\mathrm{ZnO}$ nanoparticles was also dissolved in chloroform. Chloroform containing $\mathrm{ZnO}$ was sonicated by ultrasonication for $1 \mathrm{hr}$ to get the uniform dispersion of $\mathrm{ZnO}$ nanoparticles in chloroform. When the P3HT was completely dissolved in chloroform then 50 wt.\% of the $\mathrm{ZnO}$ was added in the chloroform solution containing P3HT. This solution was thoroughly stirred for $24 \mathrm{hrs}$. Then prepared solution was again sonicated by ultrasonicator for one hour to get the uniform dispersion of $\mathrm{ZnO}$ nanoparticles in $\mathrm{P} 3 \mathrm{HT}$ solution. After this, the film of $\mathrm{P} 3 \mathrm{HT} / \mathrm{ZnO}$ composite has been deposited by spin coating on ITO, which was cleaned several times with methanol, acetone, and deionized water, at $2000 \mathrm{rpm}$ for 1 minute and $4000 \mathrm{rpm}$ for 1 minute consequently to modify the surface of device. The $\mathrm{Al}$ electrode was then deposited on the top of $\mathrm{P} 3 \mathrm{HT} / \mathrm{ZnO}$ film at high vacuum. So prepared P3HT/ZnO solar cell was annealed at $100^{\circ} \mathrm{C}$ temperatures for a period of 5 minutes under vacuum. After 5 minutes, the device was left in the vacuum in order to cool down to room temperature and then the measurements were performed.

2.3. Characterization Techniques. XRD measurement was performed with Philips X'pert X-ray diffractometer at a scanning rate of $3^{\circ}$ per minute between 10 and $70^{\circ}$. The source used for this study was $\mathrm{Cu}, \mathrm{K} \alpha(\lambda=1.5406 \AA)$ operated at $40 \mathrm{~mA}$ and $45 \mathrm{kV}$.

TEM measurement was performed on Tecnai G2 $30 \mathrm{U}$ Twin system operating at an accelerating voltage of $200 \mathrm{kV}$. The sample for TEM measurement was prepared by dispersing the $\mathrm{ZnO}$ nanoparticles in chloroform using ultrasonicator. A drop of prepared solution was placed on the carbon coated copper grid and the solvent was removed by evaporation at room temperature before the TEM measurement.

SEM image of $\mathrm{ZnO}$ nanoparticles in powder form was obtained on Carl Zeiss EVO 18 SEM system with an accelerating voltage of $20 \mathrm{kV}$.

The optical absorption spectra of $\mathrm{ZnO}$ nanoparticles, $\mathrm{P} 3 \mathrm{HT}$, and $\mathrm{P} 3 \mathrm{HT} / \mathrm{ZnO}$ solar cell were recorded over the wavelength range from 300 to $800 \mathrm{~nm}$ using Shimadzu spectrophotometer model 1800.

Current-voltage $(I-V)$ measurement was taken in air at room temperature using Keithley electrometer 6517 A. For photovoltaic characterization, the $\mathrm{P} 3 \mathrm{HT} / \mathrm{ZnO}$ solar cell was illuminated with $10 \mathrm{~mW} / \mathrm{cm}^{2}$ white light illumination from a halogen lamp through the glass/ITO side. The calculation of the power conversion efficiency $(\eta)$ has been performed using the equation

$$
\eta=\frac{V_{\mathrm{oc}} I_{\mathrm{sc}} \mathrm{FF}}{P_{\mathrm{in}}},
$$

where $V_{\mathrm{oc}}, I_{\mathrm{sc}}, \mathrm{FF}$, and $P_{\text {in }}$ are the open circuit voltage, the short circuit current density, the fill factor, and power of the incident light.

The fill factor (FF) measures the quality of the solar cell as a power source and is defined as the ratio between the 


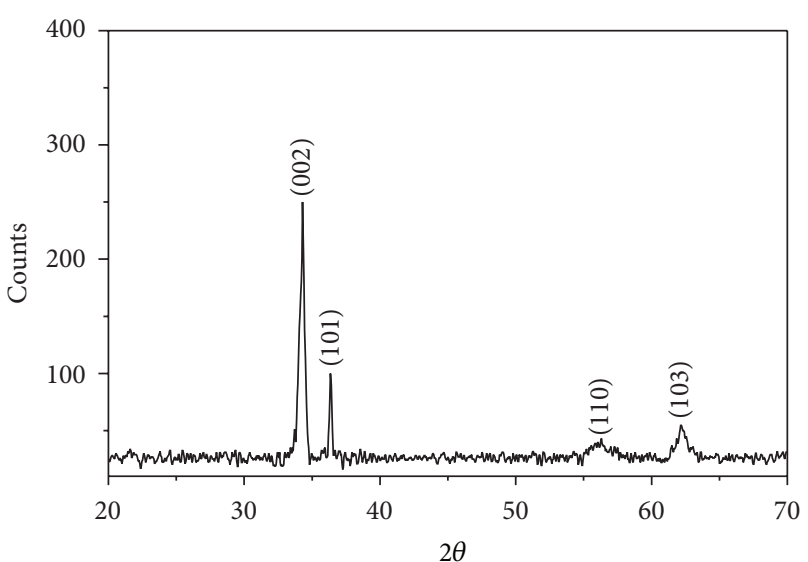

FIGURE 1: XRD of monodispersed $\mathrm{ZnO}$ nanoparticles.

maximum power delivered to an external circuit and the potential power according to

$$
\mathrm{FF}=\frac{V_{\max } I_{\max }}{V_{\mathrm{oc}} I_{\mathrm{sc}}},
$$

where $V_{\max }$ and $I_{\max }$ are the values of the current density and voltage for maximizing the product of the $I-V$ curve in the fourth quadrant, where the device operates as an electrical power source.

\section{Results and Discussion}

Figure 1 shows the XRD pattern of $\mathrm{ZnO}$, synthesized in alcohol medium. The peaks observed at $2 \theta=34.03^{\circ}, 36.35^{\circ}$, $56.36^{\circ}$, and $62.25^{\circ}$ corresponding to the lattice planes (002), (101), (110), and (103), respectively, are indicative of wurtzite hexagonal structure of $\mathrm{ZnO}$. All the peaks are matched with standard JCPDS card no. 361451. It seems that these $\mathrm{ZnO}$ particles possess a high crystallinity, since all the peaks are very sharp. No additional peaks of impurities were detected in the XRD pattern indicating the high purity of prepared nanoparticles.

The morphology of $\mathrm{ZnO}$ nanoparticles was investigated by TEM and SEM. The TEM images are shown in Figures 2(a) and 2(b) at 200 and $100 \mathrm{~nm}$ scale bar, respectively. The structure and shape of the particles are measured from the TEM measurement. The shape of particles is spherical as observed from TEM image. It is observed that the particles are well separated and distinguishable from each other. The obtained $\mathrm{ZnO}$ nanoparticles are monodispersed with $8 \mathrm{~nm}$ average particle size and size distribution of $\mathrm{ZnO}$ nanoparticles is shown in Figure 2(c). Figure 3 shows the SEM image of $\mathrm{ZnO}$ nanoparticles. The image also depicts the nearly spherical morphology of the particles.

Figure 4 shows the absorption spectra of pure $\mathrm{P} 3 \mathrm{HT}$, $\mathrm{ZnO}$ nanoparticles, and 50:50 wt.\% P3HT/ZnO solar cells annealed at $100^{\circ} \mathrm{C}$ for 5 minute in vacuum. In the absorption spectrum of pure $\mathrm{P} 3 \mathrm{HT}$, the original absorption of $\mathrm{P} 3 \mathrm{HT}$ centred at $550 \mathrm{~nm}$ and $512 \mathrm{~nm}$ corresponds to $\pi-\pi^{*}$ transition, which is due to the $0-0$ and the $0-1$ transitions, respectively, where $0-n$ means a vibronic transition from the ground vibrational state of the ground singlet electronic state to the $n$th vibrational state of the first excited singlet electronic state and is in very good agreement with values reported in the literature $[38,39]$. The transitions $(0-0)$ and $(0-1)$ are associated with the interchain and intrachain packing orders, respectively [40]. A peak corresponding to $315 \mathrm{~nm}(3.93 \mathrm{eV})$ is observed in absorption spectrum of monodispersed $\mathrm{ZnO}$ nanoparticles, which indicates the blue shifting of absorption peak as compared to its bulk counterpart. This confirms the nanostructure of the prepared $\mathrm{ZnO}$.

As the $50 \mathrm{wt} . \% \mathrm{ZnO}$ nanoparticles are added in $\mathrm{P} 3 \mathrm{HT}$, an increment in the relative intensity of absorption is observed and sharp shoulder at $600 \mathrm{~nm}$ is also observed in Figure 4, which is also due to P3HT [39]. It is clear that the insertion of $\mathrm{ZnO}$ nanoparticles modify the absorption spectrum. This means that polymer conformation is strongly modified by its interaction with $\mathrm{ZnO}$ nanoparticles. The incorporation of $\mathrm{ZnO}$ nanoparticles modifies the polymer structure promoting polymer ordering (higher crystallinity) [41]. Moreover, this order increases interchain interactions in composite of $\mathrm{P} 3 \mathrm{HT}$ and $\mathrm{ZnO}$ nanoparticles compared to the pure polymer. The shoulder at $600 \mathrm{~nm}(2.02 \mathrm{eV})$ represents a transition of a different nature. Brown et al. [38] showed compelling evidence that this transition can be attributed to an interchain absorption, corresponding to the formation of an exciton delocalized over multiple P3HT chains, the intensity of which is correlated with the degree of (torsional) order in the polymer. The presence of this shoulder indicates the enhanced hole mobility in the polymer [42].

In order to make use of monodispersed $\mathrm{ZnO}$ nanoparticles in solar cell application, $\mathrm{ZnO}$ nanoparticles have been blended with P3HT taking 50:50 wt.\%. The current densityvoltage $(J-V)$ characteristic curve has been recorded using Keithley electrometer under the illumination intensity of $10 \mathrm{~mW} / \mathrm{cm}^{2}$. The obtained result is plotted in Figure 5. Inset in Figure 5 shows the $J-V$ characteristic curve in dark. The cell parameters of the device such as power conversion efficiency, open circuit voltage, short circuit current density, and fill factor have been determined using the $J-V$ characteristic curve under illumination condition. The photovoltaic performance of the solar cell shows a short circuit current density of $0.56 \mathrm{~mA} / \mathrm{cm}^{2}$, an open circuit voltage of $0.40 \mathrm{~V}$, and fill factor of 0.40 . The power conversion efficiency of $0.88 \%$ is obtained for $\mathrm{P} 3 \mathrm{HT} / \mathrm{ZnO}$ solar cell, which is comparable with the result reported by other workers [43].

\section{Conclusions}

The following conclusions have been drawn from the above studies.

(1) Monodispersed $\mathrm{ZnO}$ nanoparticles of hexagonal wurtzite structure with an average size of $8 \mathrm{~nm}$ were synthesized at room temperature by ultrasonic treatment using ethylene glycol as reaction medium and zinc acetate and sodium hydroxide as reactants.

(2) A film of P3HT/ZnO composite deposited by spin coating can serve as a solar cell. 


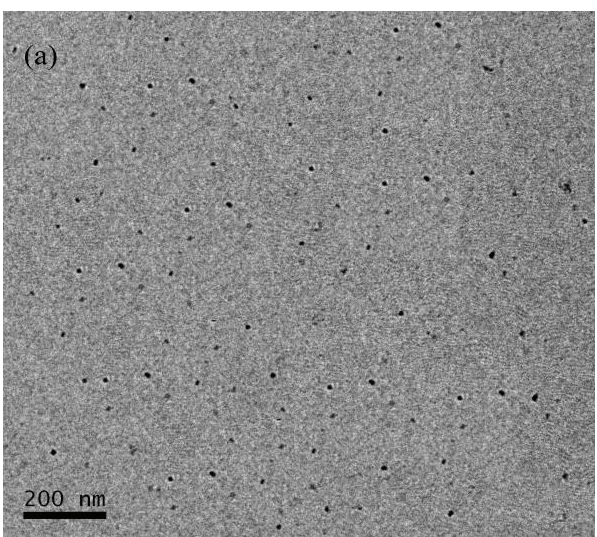

(a)

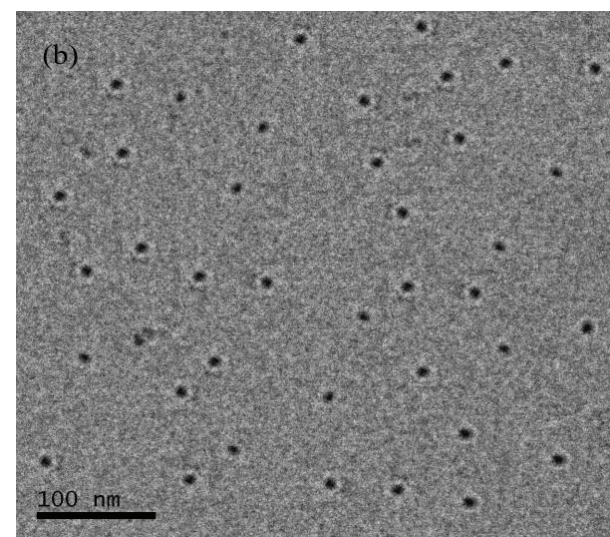

(b)

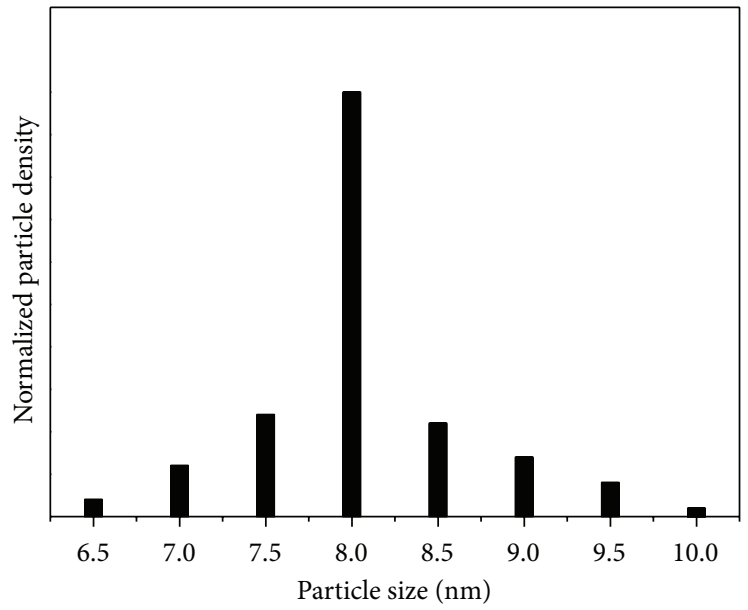

(c)

Figure 2: TEM images of ZnO nanoparticles at (a) $200 \mathrm{~nm}$ scale bar, (b) $100 \mathrm{~nm}$ scale bar, and (c) size distribution of ZnO nanoparticles.

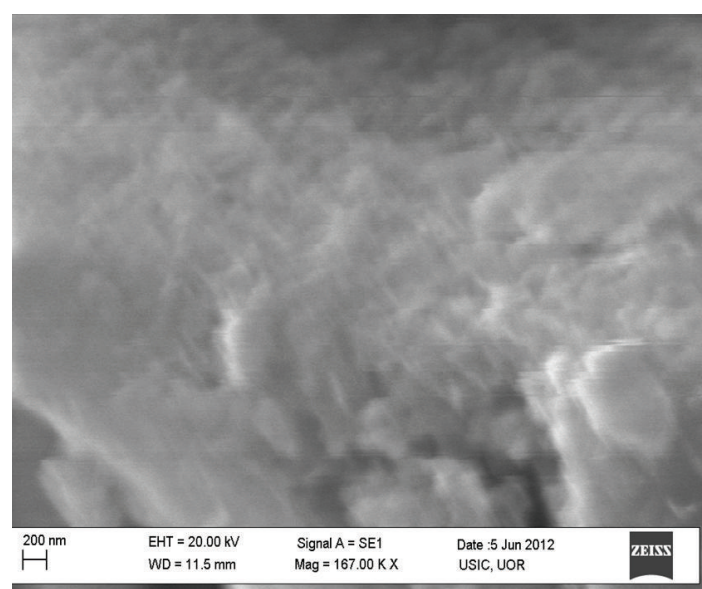

FIgURE 3: SEM images of $\mathrm{ZnO}$ nanoparticles.

(3) An increase in the intensity of absorption spectrum of $\mathrm{P} 3 \mathrm{HT} / \mathrm{ZnO}$ as compared to $\mathrm{P} 3 \mathrm{HT}$ indicates the improvement of interchain and intrachain ordering of $\mathrm{P} 3 \mathrm{HT}$ with the addition of $\mathrm{ZnO}$.

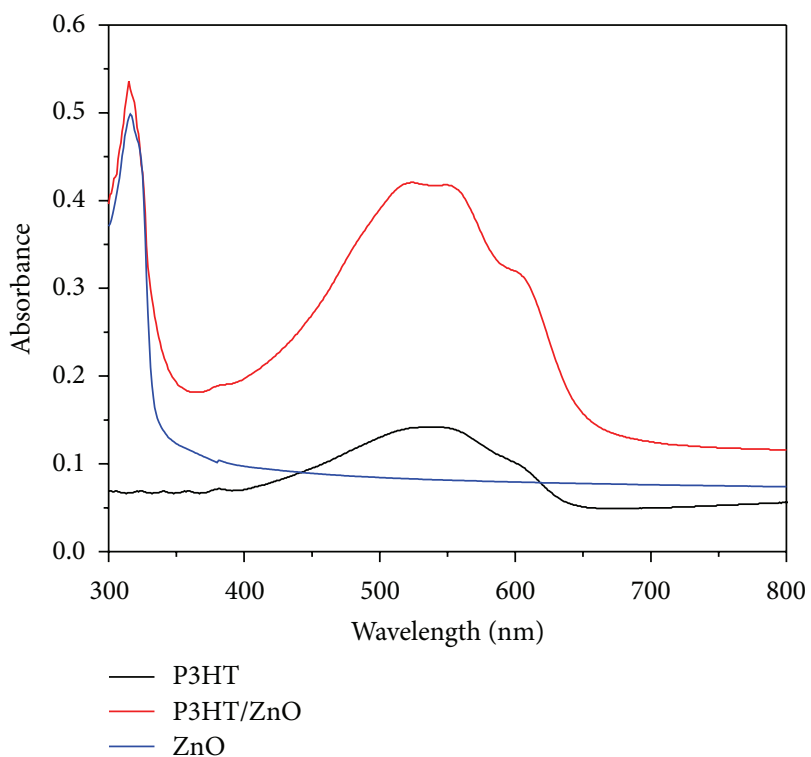

Figure 4: Absorption spectra of $\mathrm{ZnO}$ nanoparticles, P3HT, and $\mathrm{P} 3 \mathrm{HT} / \mathrm{ZnO}$ solar cell. 


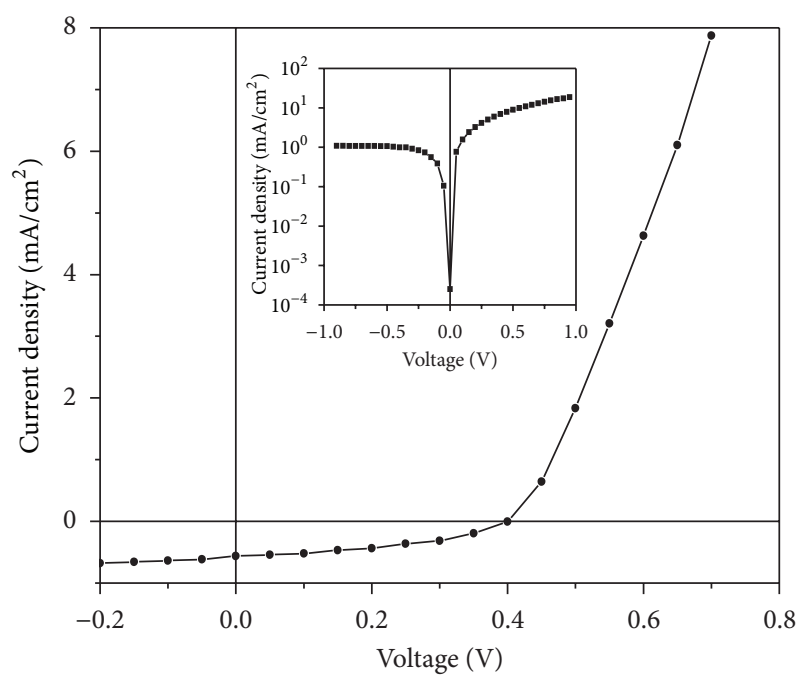

FIGURE 5: Current density-voltage characteristic of P3HT/ZnO solar cell under illumination and inset under dark.

(4) The power conversion efficiency of fabricated solar cell is comparable with the efficiency of other solar cells reported in the literature.

\section{Acknowledgment}

One of the authors, D. Patidar, is thankful to DST, New Delhi, for providing financial assistance during the course of this work.

\section{References}

[1] G. Schmid, Nanoparticles: From Theory to Application, WileyVCH, Weinheim, Germany, 2004.

[2] K. J. Klabunde, Nanoscale Materials in Chemistry, WileyInterscience, New York, NY, USA, 2001.

[3] A. P. Alivisatos, "Semiconductor clusters, nanocrystals, and quantum dots," Science, vol. 271, no. 5251, pp. 933-937, 1996.

[4] J. Zhong, A. H. Kitai, and P. Mascher, "Influence of processing conditions on point defects and luminescence centers in $\mathrm{ZnO}$," Journal of the Electrochemical Society, vol. 140, no. 12, pp. 36443649, 1993.

[5] M. H. Huang, S. Mao, H. Feick et al., "Room-temperature ultraviolet nanowire nanolasers," Science, vol. 292, no. 5523, pp. 1897-1899, 2001.

[6] M. Yoshimoto, S. Takagi, Y. Umemura, M. Hada, and H. Nakatsuji, "Theoretical study on the decomposition of $\mathrm{HCOOH}$ on a $\mathrm{ZnO}(1010)$ surface," Journal of Catalysis, vol. 173, no. 1, pp. 53-63, 1998.

[7] H. Kind, H. Yan, B. Messer, M. Law, and P. Yang, "Nanowire ultraviolet photodetectors and optical switches," Advanced Materials, vol. 14, pp. 158-160, 2002.

[8] M. Lakshmi Kantam, K. B. Shiva Kumar, and C. Sridhar, "Nanocrystalline $\mathrm{ZnO}$ as an efficient heterogeneous catalyst for the synthesis of 5-substituted $1 \mathrm{H}$-tetrazoles," Advanced Synthesis and Catalysis, vol. 347, no. 9, pp. 1212-1214, 2005.

[9] T. Minami, "New $n$-type transparent conducting oxides," MRS Bulletin, vol. 25, no. 8, pp. 38-44, 2000.
[10] E. Olsson, G. Dunlop, and R. Osterlund, "Development of functional microstructure during sintering of a $\mathrm{ZnO}$ varistor material," Journal of the American Ceramic Society, vol. 76, no. 1, pp. 65-71, 1993.

[11] M. C. Newton, S. Firth, and P. A. Warburton, "Photoresponse of $\mathrm{ZnO}$ tetrapod nanocrystal Schottky diodes," IEEE Transactions on Nanotechnology, vol. 7, no. 1, pp. 20-23, 2008.

[12] E. Sun, F.-H. Su, Y.-T. Shih et al., "An efficient Si light-emitting diode based on an $n-\mathrm{ZnO} / \mathrm{SiO}_{2}-\mathrm{Si}$ nanocrystals- $\mathrm{SiO}_{2} / \mathrm{p}-\mathrm{Si}$ heterostructure," Nanotechnology, vol. 20, no. 44, Article ID 445202, 2009.

[13] C. Lévy-Clément, R. Tena-Zaera, M. A. Ryan, A. Katty, and G. Hodes, "CdSe-sensitized p-CuSCN/nanowire n-ZnO heterojunctions," Advanced Materials, vol. 17, no. 12, pp. 1512-1515, 2005.

[14] P. Ravirajan, A. M. Peiró, M. K. Nazeeruddin et al., "Hybrid polymer/zinc oxide photovoltaic devices with vertically oriented $\mathrm{ZnO}$ nanorods and an amphiphilic molecular interface layer," Journal of Physical Chemistry B, vol. 110, no. 15, pp. 76357639, 2006

[15] W. J. E. Beek, M. M. Wienk, and R. A. J. Janssen, "Hybrid polymer solar cells based on zinc oxide," Journal of Materials Chemistry, vol. 15, no. 29, pp. 2985-2988, 2005.

[16] D. C. Olson, J. Piris, R. T. Collins, S. E. Shaheen, and D. S. Ginley, "Hybrid photovoltaic devices of polymer and $\mathrm{ZnO}$ nanofiber composites," Thin Solid Films, vol. 496, no. 1, pp. 26-29, 2006.

[17] A. M. Peiró, P. Ravirajan, K. Govender et al., "The effect of zinc oxide nanostructure on the performance of hybrid polymer/zinc oxide solar cells," in Organic Photovoltaics VI, vol. 5938 of Proceedings of the SPIE, pp. 1-8, August 2005.

[18] J. Park, K. An, Y. Hwang et al., "Ultra-large-scale syntheses of monodisperse nanocrystals," Nature Materials, vol. 3, no. 12, pp. 891-895, 2004.

[19] R. He and T. Tsuzuki, "Low-temperature solvothermal synthesis of $\mathrm{ZnO}$ quantum dots," Journal of the American Ceramic Society, vol. 93, no. 8, pp. 2281-2285, 2010.

[20] H. Yong, J. Zhimin, X. Chengdong, M. Ting, G. Jun, and W. Tim, "Monodisperse $\mathrm{ZnO}$ nanodots: synthesis, charaterization, and optoelectronic properties," Journal of Physical Chemistry C, vol. 111, no. 27, pp. 9757-9760, 2007.

[21] Y. Hu, T. Mei, J. Guo, and T. White, "Temperature-triggered selfassembly of $\mathrm{ZnO}$ : from nanocrystals to nanorods to tablets," Inorganic Chemistry, vol. 46, no. 26, pp. 11031-11035, 2007.

[22] A. Umar, S. H. Kim, Y.-S. Lee, K. S. Nahm, and Y. B. Hahn, "Catalyst-free large-quantity synthesis of $\mathrm{ZnO}$ nanorods by a vapor-solid growth mechanism: structural and optical properties," Journal of Crystal Growth, vol. 282, no. 1-2, pp. 131-136, 2005.

[23] L. Shen, L. Guo, N. Bao, and K. Yanagisawa, "Salt-assisted solid-state chemical reaction synthesis of $\mathrm{ZnO}$ nanocrystals," Chemistry Letters, vol. 32, no. 9, pp. 826-827, 2003.

[24] D. Wang, H. W. Seo, C.-C. Tin et al., "Effects of postgrowth annealing treatment on the photoluminescence of zinc oxide nanorods," Journal of Applied Physics, vol. 99, no. 11, Article ID 113509, 2006.

[25] W. I. Park, D. H. Kim, S.-W. Jung, and G.-C. Yi, "Metalorganic vapor-phase epitaxial growth of vertically well-aligned $\mathrm{ZnO}$ nanorods," Applied Physics Letters, vol. 80, no. 22, pp. 42324234, 2002.

[26] J. Y. Park, D. J. Lee, and S. S. Kim, "Size control of ZnO nanorod arrays grown by metalorganic chemical vapour deposition," Nanotechnology, vol. 16, no. 10, pp. 2044-2047, 2005. 
[27] Y. Li, G. W. Meng, L. D. Zhang, and F. Phillipp, “Ordered semiconductor $\mathrm{ZnO}$ nanowire arrays and their photoluminescence properties," Applied Physics Letters, vol. 76, no. 15, pp. 2011-2013, 2000.

[28] Y.-Y. Peng, T.-E. Hsieh, and C.-H. Hsu, "Effects of interface bonding configuration on photoluminescence of $\mathrm{ZnO}$ quantum dots-SiOxNy nanocomposite films," Journal of Materials Research, vol. 23, no. 4, pp. 1155-1162, 2008.

[29] W. Q. Peng, S. C. Qu, G. W. Cong, and Z. G. Wang, "Synthesis and structures of morphology-controlled $\mathrm{ZnO}$ nano- and microcrystals," Crystal Growth and Design, vol. 6, no. 6, pp. 1518-1522, 2006.

[30] Z. Q. Zhang and J. Mu, "Fabrication of $\mathrm{ZnO}$ nanorods in colloidal systems formed by PEO-PPO-PEO block copolymers," Journal of Dispersion Science and Technology, vol. 27, no. 6, pp. 769-772, 2006.

[31] R.-L. Liu, Q. Xiang, Q.-Y. Pan, Z.-X. Cheng, and L.-Y. Shi, "Hydrothermal synthesis and gas sensitivity of one-dimensional ZnO," Journal of Inorganic Materials, vol. 21, no. 4, pp. 793-796, 2006.

[32] T. Andelman, Y. Gong, M. Polking et al., "Morphological control and photoluminescence of zinc oxide nanocrystals," Journal of Physical Chemistry B, vol. 109, no. 30, pp. 14314-14318, 2005.

[33] Y. Chen, M. Kim, G. Lian, M. B. Johnson, and X. Peng, "Side reactions in controlling the quality, yield, and stability of high quality colloidal nanocrystals," Journal of the American Chemical Society, vol. 127, no. 38, pp. 13331-13337, 2005.

[34] J. P. Cheng, X. B. Zhang, X. Y. Tao, H. M. Lu, Z. Q. Luo, and F. Liu, "Fine-tuning the synthesis of $\mathrm{ZnO}$ nanostructures by an alcohol thermal process," Journal of Physical Chemistry B, vol. 110, no. 21, pp. 10348-10353, 2006.

[35] L. Spanhel and M. A. Anderson, "Semiconductor clusters in the sol-gel process: quantized aggregation, gelation, and crystal growth in concentrated $\mathrm{ZnO}$ colloids," Journal of the American Chemical Society, vol. 113, no. 8, pp. 2826-2833, 1991.

[36] D. Qian, J. Z. Jiang, and P. L. Hansen, "Preparation of $\mathrm{ZnO}$ nanocrystals via ultrasonic irradiation," Chemical Communications, vol. 9, no. 9, pp. 1078-1079, 2003.

[37] M. Y. Ge, H. P. Wu, L. Niu et al., "Nanostructured ZnO: from monodisperse nanoparticles to nanorods," Journal of Crystal Growth, vol. 305, no. 1, pp. 162-166, 2007.

[38] P. J. Brown, D. S. Thomas, A. Köhler et al., "Effect of interchain interactions on the absorption and emission of poly(3hexylthiophene)," Physical Review B, vol. 67, no. 6, Article ID 064203, 2003.

[39] J.-F. Chang, J. Clark, N. Zhao et al., "Molecular-weight dependence of interchain polaron delocalization and exciton bandwidth in high-mobility conjugated polymers," Physical Review $B$, vol. 74, no. 11, Article ID 115318, 2006.

[40] J. Bouclé, H. J. Snaith, and N. C. Greenham, "Simple approach to hybrid polymer/porous metal oxide solar cells from solutionprocessed ZnO nanocrystals," Journal of Physical Chemistry C, vol. 114, no. 8, pp. 3664-3674, 2010.

[41] D. C. Olson, Y.-J. Lee, M. S. White et al., "Effect of polymer processing on the performance of poly(3-hexylthiophene)/ $\mathrm{ZnO}$ nanorod photovoltaic devices," Journal of Physical Chemistry C, vol. 111, no. 44, pp. 16640-16645, 2007.

[42] S. Cho, K. Lee, J. Yuen et al., "Thermal annealing-induced enhancement of the field-effect mobility of regioregular poly(3hexylthiophene) films," Journal of Applied Physics, vol. 100, no. 11, Article ID 114503, 2006.
[43] W. J. E. Beek, M. M. Wienk, and R. A. J. Janssen, "Hybrid solar cells from regioregular polythiophene and $\mathrm{ZnO}$ nanoparticles," Advanced Functional Materials, vol. 16, no. 8, pp. 1112-1116, 2006. 

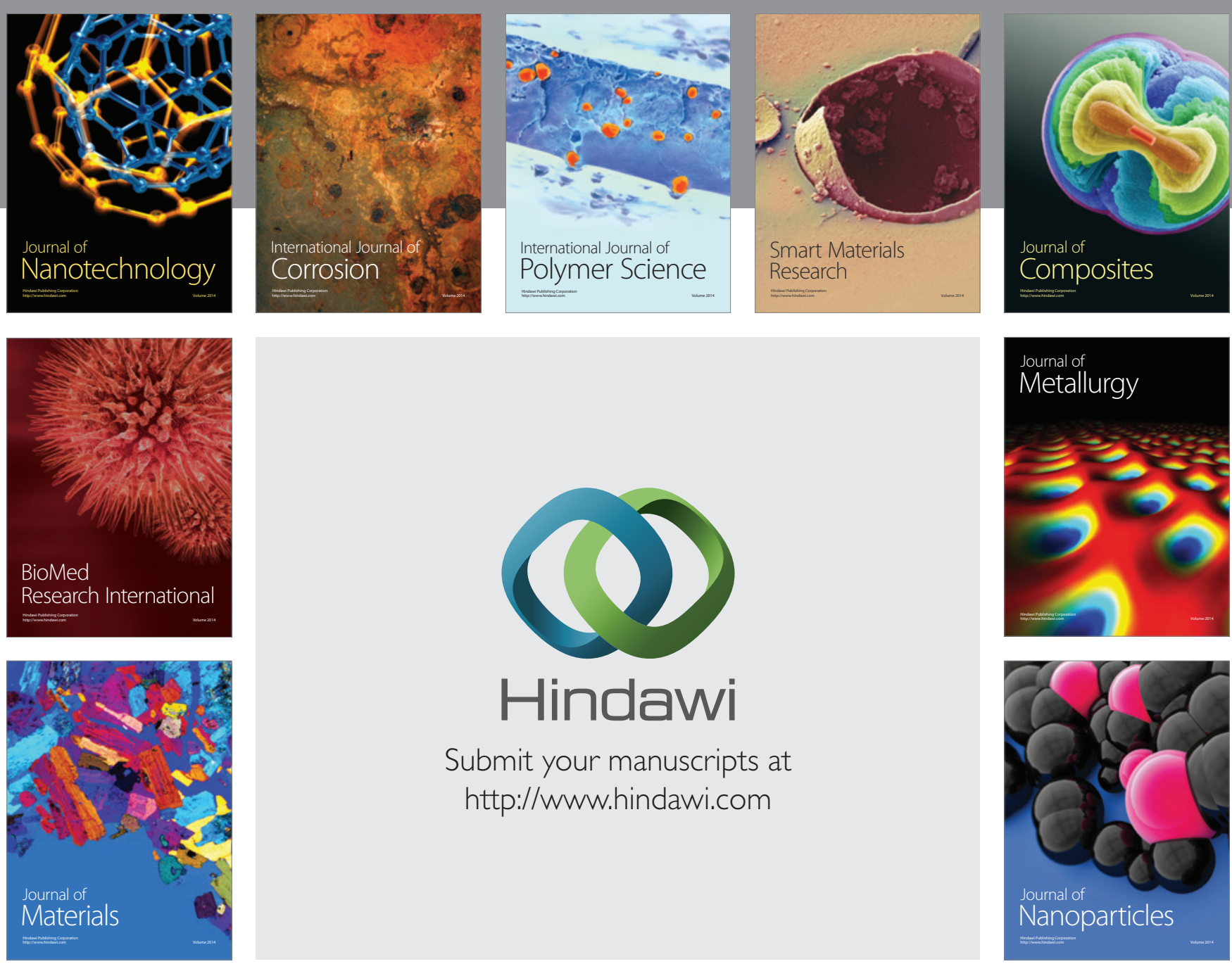

Submit your manuscripts at http://www.hindawi.com
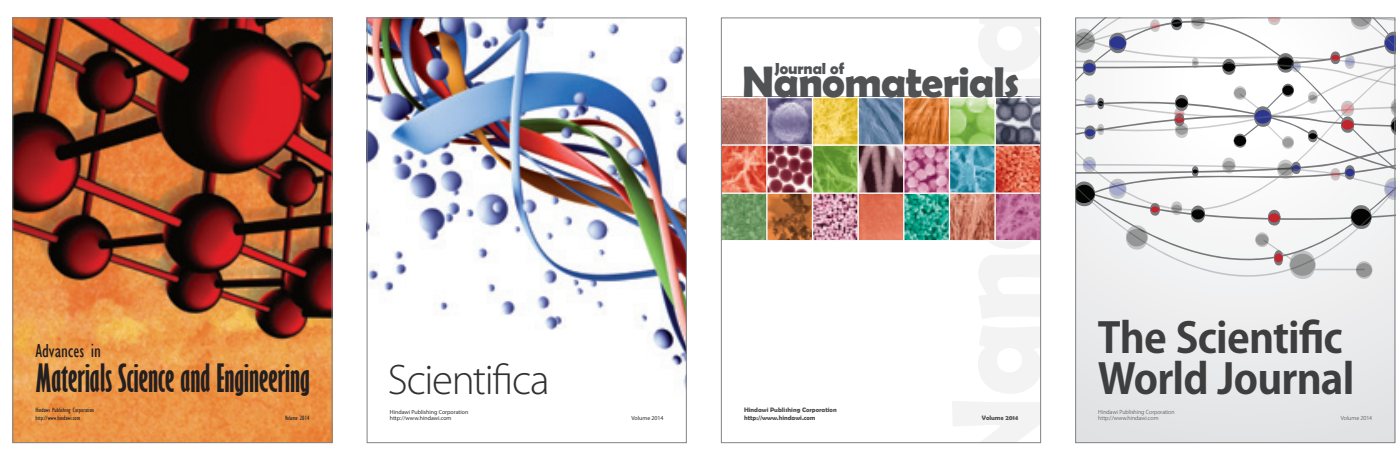

\section{The Scientific World Journal}
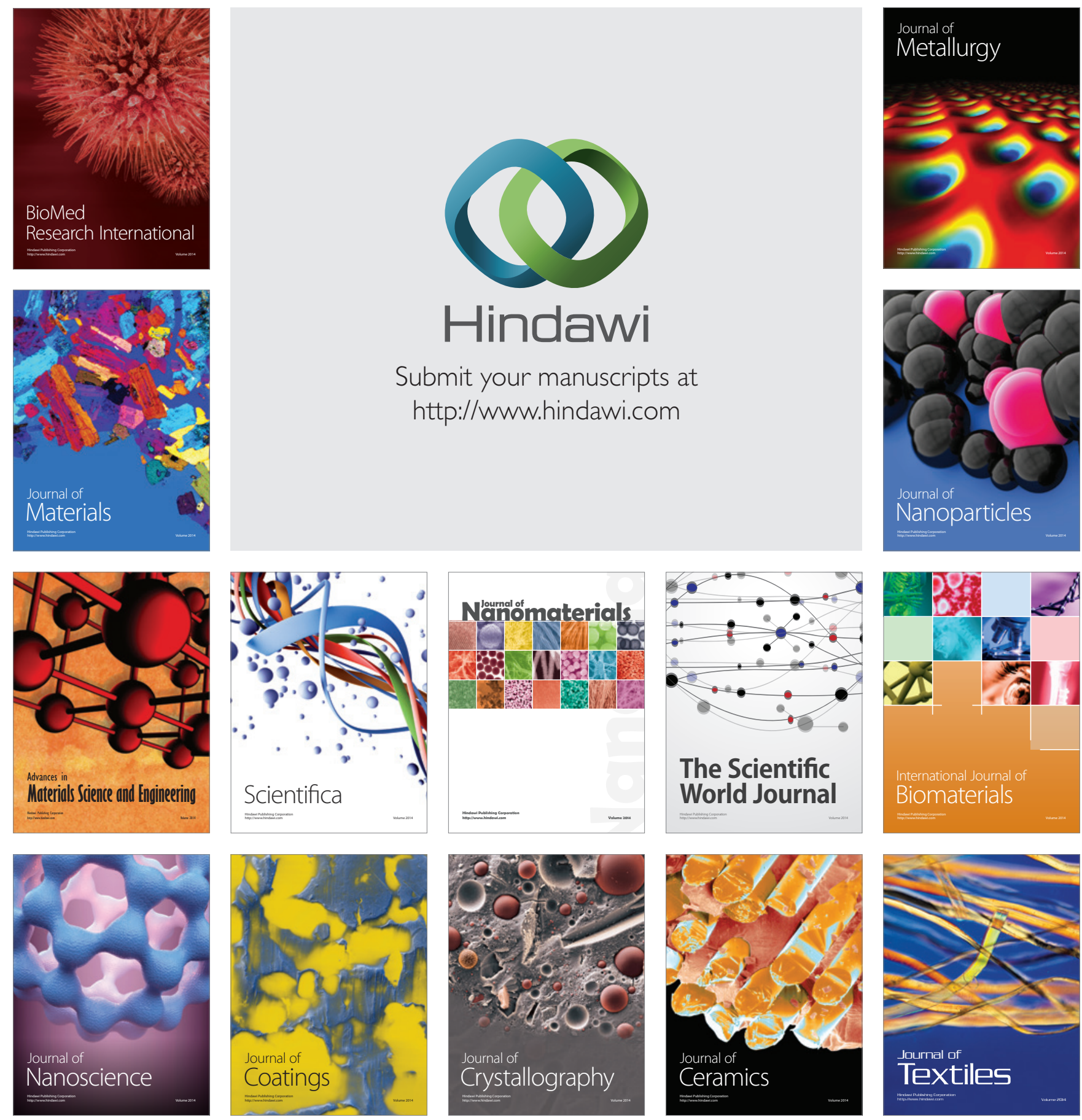